\title{
Substituent and Solvent Effects on HCN Elimination from 1-Aryl-1,2,2-tricyanoethanes [1]
}

Fouad M. Fouad

Max-Planck-Institut für Biochemie, D-8033 Martinsried bei München, West Germany

and

Patrick G. Farrell

Department of Chemistry, McGill University, Montreal, Quebec, Canada, H3 A 2 K 6

Z. Naturforsch. 34 b, 86-94 (1979); received August 2, 1978

\section{1,2,2-Tricyanoethanes, Elimination of $\mathrm{HCN}$}

The elimination of HCN from 9-dicyanomethyl-fluorene (2), I,I-diphenyl-I,2,2tricyanoethane (3), and 2-phenyl-I,1,2-tricyano-propane (4) in anhydrous methanol has been studied and shown to occur via an (E 1)anion mechanism. Elimination of HCN from 2 in acidic, buffered and $\mathrm{MeO}^{-} / \mathrm{MeOH}$ solutions have also been studied. Addition of water or benzene to the reaction medium shifts the mechanism to $(\mathrm{E} 1 \mathrm{cB})_{\mathrm{R}}$. Elimination of HCN from N,N-dimethyl-4-(I,I,2-tricyanoethyl) aniline (5) in anhydrous methanol occurs via an $(\mathrm{E} \mathrm{I} \mathrm{cB})_{\mathrm{R}}$ mechanism and the kinetics indicate that addition of $\mathrm{HCN}$ to the product alkene occurs. Activation parameters, isotope effects and solvent effects have been examined in an effort to obtain inf ormation about the nature of the transition states of these reactions.

\section{Introduction}

The base catalyzed elimination of HCN from various polycyanoethane derivatives has been the subject of several mechanistic investigations because of the potential stabilization of an intermediate carbanion in such systems, thus favouring elimina- tion via the $\mathrm{El} \mathrm{cB}$ mechanism [2-5]. Within the overall $\mathrm{E} 1 \mathrm{cB}$ mechanistic scheme a number of possible rate-determining steps may be envisaged, giving rise to different kinetic schemes, and examples of elimination via each of these pathways have been reported [6].

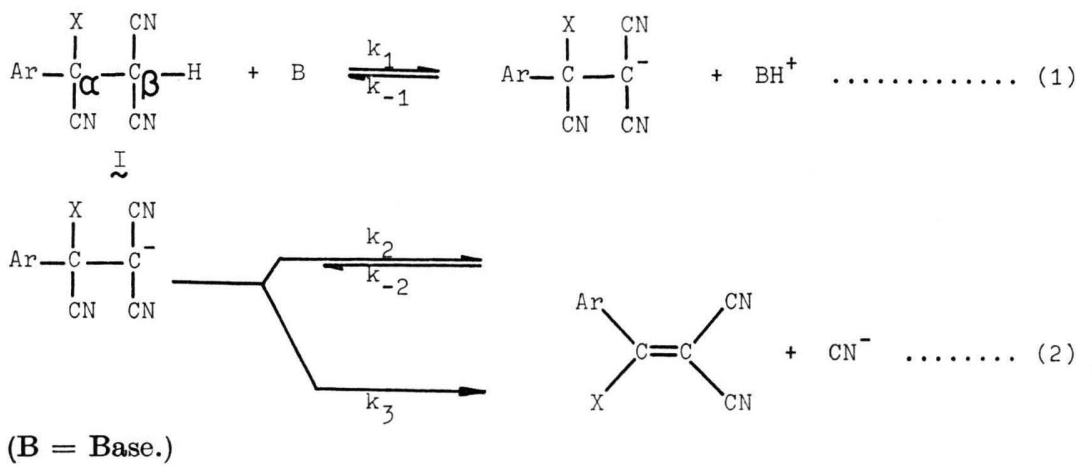

According to the simple scheme shown in equations (1) and (2) either formation of the carbanion, or ejection of leaving (cyano) group thereform, may be rate-determining $[4,6]$ and the observed kinetics may be further complicated by the reverse reactions denoted by $\mathrm{k}_{-2}$ and $\mathrm{k}_{-1}$. That $\mathrm{k}_{-2}$ represents the reverse of $\mathrm{E} 1 \mathrm{cB}$ elimination has been confirmed, both by the method of synthesis of cyanoethane

Requests for reprints should be sent to Dr. Fouad M. Fouad, Max-Planck-Institut für Biochemie, D.8033 Martinsried bei München.

derivatives and by numerous studies of nucleophilic vinylic substitution of ethylenes carrying electronwithdrawing groups by Rappoport and co-workers [7].

In an earlier study of the effect of the medium upon $\mathrm{HCN}$ elimination from $\left(\mathrm{Ar}=4-\mathrm{Me}_{2} \mathrm{~N}-\mathrm{C}_{6} \mathrm{H}_{4-}\right.$, $\mathrm{X}=-\mathrm{CN}$ ) we found that reaction occurred in various solvent mixtures in the absence of added base, indicating that the $\beta$-hydrogen atom is indeed highly acidic [8]. We has assumed that this acidity was due predominantly to the two $\beta$-cyano groups, and that the $\alpha$-X substituents would affect only the 
elimination rate and not the basic elimination mechanism. That this assumption may be invalid is suggested by the leaving group effects found in various substitution reactions [7]. Therefore we have examined the influence of the $\alpha$-substituent in some $\mathrm{HCN}$ elimination reactions, on rate coefficients and the mechanistic course of elimination within the $\mathrm{ElcB}$ variants, notably those from 9 -cyano9-dicyanomethyl-fluorene (2), 1,1-diphenyl-1,2,2tricyanoethane (3), 2-phenyl-1,1,2-tricyanopropane (4) and N,N-dimethyl-4-(1,1,2-tricyanoethyl)aniline (5).
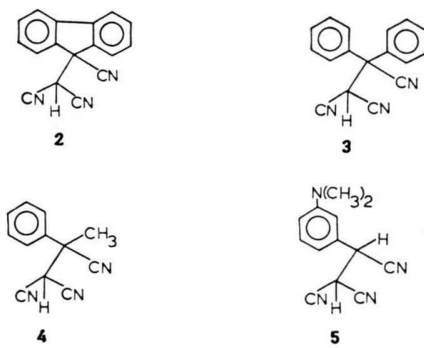

\section{Experimental}

Materials: Polycyanides (1)-(4) were prepared according to the standard methods [9], (2-D)-(5-D) were prepared either via exchange of $\beta$-hydrogen atom of the polycyanides with deuterium oxide, followed by extraction of the product into $\mathrm{CDCl}_{3}$ or by rapid crystallization of the cyano-compound from methan- $\left[{ }^{2} \mathrm{H}_{1}\right]$-ol [1].

Fisher spectrograde methanol and methan$\left[{ }^{2} \mathrm{H}_{1}\right]$-ol (Merck, Sharp and Dohme) were doubly distilled samples purified according to Vogel [10]. Samples of methanol prepared according to this method showed to contain less than $10^{-6}$ basic or acidic impurities similar to samples purified according to Ritchie [11].
Kinetic procedure: Fresh solutions of 2-5 were prepared daily.The starting substrate concentration was $\sim 10^{-4} \mathrm{~mol} \mathrm{l}^{-1}$. The run was followed by measuring the $\lambda_{\max }$ absorbance of the product. Error in specific rate coefficients is in the range of $\pm 1 \%$. However, some reproducibility problems arose when the reactions were carried out entirely within the silica cell, presumably because of the relatively large surface area and the long reaction times. Samples of stock solutions were therefore taken at various time intervals and their optical densities measured. For further details see previous paper [1].

Table Ia and Ib. Rate coefficients and derived enthalpies for HCN elimination from 2 in various solvents.

\begin{tabular}{|c|c|c|c|c|}
\hline $\begin{array}{l}\text { Ia } \\
\text { Solvent }\end{array}$ & $\mathrm{t}\left[{ }^{\circ} \mathrm{C}\right]$ & $10^{4}[2] / \mathrm{M}$ & $10^{9} \mathrm{k}_{0}$ & $\Delta \mathrm{H} \neq / \mathrm{kJ} \mathrm{M}^{-1}$ \\
\hline Methanol & $\begin{array}{l}25 \\
30 \\
35\end{array}$ & $\begin{array}{l}1.0 \\
1.156 \\
1.039\end{array}$ & $\begin{array}{l}4.28 \\
8.5 \\
23.85\end{array}$ & $125 \pm 9$ \\
\hline $\begin{array}{c}\text { Methanol/ } \\
(9: \mathrm{I})\end{array}$ & $\begin{array}{l}25 \\
30 \\
35\end{array}$ & $\begin{array}{l}1.0 \\
1.078 \\
1.031\end{array}$ & $\begin{array}{r}7.76 \\
14.06 \\
38.07\end{array}$ & $116 \pm 10$ \\
\hline$(4: I)$ & $\begin{array}{l}25 \\
30 \\
35\end{array}$ & $\begin{array}{l}\text { I.II7 } \\
\text { I.063 } \\
\text { I.I02 }\end{array}$ & $\begin{array}{l}10.34 \\
19.52 \\
51.4\end{array}$ & $117 \pm 8$ \\
\hline
\end{tabular}

Ib

Solvent $\quad \mathrm{t}\left[{ }^{\circ} \mathrm{C}\right] \quad 10^{4}[2] / \mathrm{M} \quad 10^{5} \mathrm{k}_{1} \Delta \mathrm{H} \neq / \mathrm{kJ} \mathrm{M}^{-1}$

Methanol/water

$(7: 3)$

$\begin{array}{llll}25 & 1.094 & 15.7 & 110 \pm 4 \\ 30 & 1.133 & 31.36 & \\ 35 & 1.0 & 71.21 & \end{array}$

$\mathrm{k}_{0}$ is zero-order values in $\mathrm{mol}^{-1} \mathrm{~m}^{-1}$;

$\mathrm{k}_{1}$ is first-order values in $\mathrm{m}^{-1}$.

Table Ic. Rate coefficients and derived enthalpies for HCN elimination from 3 and 4 in various solvents.

\begin{tabular}{|c|c|c|c|c|c|c|c|}
\hline Solvent & $\mathrm{t}\left[{ }^{\circ} \mathbf{C}\right]$ & $10^{9}[3] / \mathrm{M}$ & $\mathrm{I} 0^{4} \mathrm{k}_{0}$ & $\Delta \mathrm{H} \neq / \mathrm{kJ} \mathbf{M}^{-1}$ & $10^{4}[4] / M$ & $\mathrm{I} 0^{9} \mathrm{k}_{0}$ & $\Delta \mathrm{H} \neq / \mathrm{kJ} \mathrm{M}^{-1}$ \\
\hline \multirow[t]{3}{*}{ Methanol } & 30 & I.03 & II.9 & \multirow{3}{*}{$109 \pm 6$} & I.I5 & 13.03 & \multirow{3}{*}{$\mathrm{II} 7 \pm \mathbf{5}$} \\
\hline & 35 & I. 143 & 22.19 & & I.23 & 25.89 & \\
\hline & 40 & I.065 & 50.85 & & I.085 & 61.61 & \\
\hline \multicolumn{8}{|c|}{ Methanol/benzene } \\
\hline \multirow{3}{*}{$\begin{array}{l}(9: I) \\
(4: I)\end{array}$} & 40 & 1.22 & 27 & & I.174 & 36.43 & \\
\hline & 40 & 1.268 & 22.84 & & I.06I & 36.83 & \\
\hline & {$\left[\mathrm{t}^{\circ} \mathrm{C}\right]$} & $10^{4}[3] / \mathrm{M}$ & $10^{5} \mathrm{k}_{1 / 2}$ & & $\mathrm{IO}^{4}[4] / \mathrm{M}$ & $\mathrm{I} 0^{5} \mathrm{k}_{1 / 2}$ & \\
\hline \multirow[t]{2}{*}{$(7: 3)$} & 40 & 1.22 & 26.03 & & I.194 & 32.25 & \\
\hline & $\mathrm{t}\left[{ }^{\circ} \mathrm{C}\right]$ & $\mathrm{I} 0^{4}[3] / \mathrm{M}$ & $10^{5} \mathrm{k}_{1}$ & & $\mathrm{I}^{4}[4] / \mathrm{M}$ & $\mathrm{I} 0^{5} \mathrm{k}_{1}$ & \\
\hline$(3: 2)$ & 40 & I.026 & 24.85 & & $1.2 \mathrm{I} 4$ & 23.36 & \\
\hline$(\mathrm{I}: \mathrm{I})$ & 40 & 1.415 & 13.4I & & 1.418 & I6.38 & \\
\hline$(2: 3)$ & 40 & & & & I.04I & 7.64 & \\
\hline$(3: 7)$ & 40 & & & & I.I63 & $4.25^{*}$ & \\
\hline
\end{tabular}

$\mathrm{k}_{0}$ is zero-order values in mol $\mathrm{l}^{-1} \mathrm{~m}^{-1} ; \mathrm{k}_{1}$ is first-order values in $\mathrm{m}^{-1} ; \mathrm{k}_{1 / 2}$ is half-order values in $\mathrm{mol}^{1 / 2} \mathrm{l}^{-1 / 2} \mathrm{~m}^{-1}$.

* Initial specific rate coefficients obtained from extrapolation. 


\section{Results and Discussion}

Elimination from 2 : The elimination of HCN from 2 in either anhydrous or aqueous methanol proceeds almost quantitatively to give 9-dicyanomethylenefluorene. There is rapid exchange of the $\beta$-hydrogen atom of $\mathbf{2}$ with deuterated solvents and the reaction follows zero-order kinetics up to $70 \%$ product formation, whereupon deviation towards higher order or equilibrium occurs, Table Ia. Unlike the reactions of the aniline derivatives studied previously [8], the reaction of 2 is very sensitive to added base. The addition of $\mathrm{CN}^{-}$(as $\mathrm{HCN}$ ) to the reaction medium depresses the rate and decreases the extent of zero-order reaction, implying an equilibrium step involving the product. The $\mathrm{CN}^{-}$addition displaces the product equllibrium to the left, and leads to first-order kinetics when the $\mathrm{CN}^{-}$concentration is large. The kinetics suggest a reaction via an $\mathrm{E} 1 \mathrm{cB}$ mechanism involving a non-steady state formation of the carbanionic intermediate. This mechanism has been denoted by Bordwell [6] as (E1)anion. To appreciate the scope of that mechanism, reactions of $\mathbf{2}$ were carried out in different media.

a) Reactions of $\mathbf{2}$ in buffered methanol, $\left(\mathrm{NEt}_{3}: \mathrm{NEt}_{3} \mathrm{HCl}\right)$, constant ratio or different concentrations of $\mathrm{NEt}_{3}$ to constant concentration of $\mathrm{NEt}_{3} \mathrm{HCl}$, or in methanol/methoxide ions resulted in faster rates of eliminations, Table IId. Plots of rate coefficients against the concentrations of added $\mathrm{NEt}_{3}: \mathrm{NEt}_{3} \mathrm{HCl}$ or methoxide ions showed a reasonable linear relation, up to $10^{-4} \mathrm{~mol} \mathrm{l}-1$ added reagent, with a fractional order $c a .0 .7$, Fig. 1 . This may indicate a general base catalysis. However, reliable rate coefficients could not be obtained when the methoxide concentrations were larger than $2.0 \times 10^{-4}$ or less than $10^{-5} \mathrm{~mol} \mathrm{l}^{-1}$.

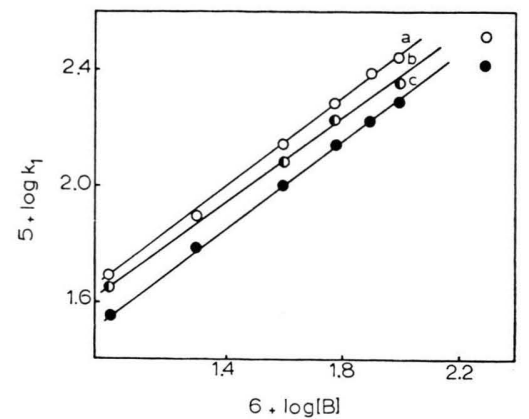

Fig. 1. Plots of $5+\log \mathrm{k}_{1}$ against $6+\log$ [base] for $\mathrm{HCN}$ elimination from 2 at $25{ }^{\circ} \mathrm{C}$ in methanol; a) $\mathrm{MeO}^{-} / \mathrm{MeOH}$, b) $\mathrm{NEt}_{3}: \mathrm{NEt}_{3} \mathrm{HCl}$ at constant $\mathrm{pH}$ and c) $\mathrm{NEt}_{3}$ at constant concentration of $\mathrm{NEt}_{3} \mathrm{HCl}$.

Table IIa. First-order rate coefficients for HCN elimination from $\mathbf{5}$ in anhydrous methanol.

\begin{tabular}{llcl}
\hline $\mathrm{t}\left[{ }^{\circ} \mathrm{C}\right]$ & $10^{4}[5] / \mathrm{M}$ & $10^{4} \mathrm{k}_{\mathrm{obs}} \mathrm{m}^{-1}$ & $\Delta \mathrm{H} \neq / \mathrm{kJ} \mathrm{M}^{-1}$ \\
\hline 25 & $\mathrm{I} .0$ & 6.19 & $59 \pm 4$ \\
30 & $\mathrm{I} .0$ & 9.77 & \\
35 & $\mathrm{I} .128$ & 14 & \\
40 & 1.0 & 20.5 & \\
\hline
\end{tabular}

Tab. IIb. First-order rate coefficients for $\mathrm{HCN}$ elimination from $\mathbf{5}$ in methanol/sodium methoxide solution.

\begin{tabular}{llll}
\hline $\mathrm{t}\left[{ }^{\circ} \mathrm{C}\right]$ & $10^{4}[5] / \mathrm{M}$ & $\mathrm{I} 0^{4}\left[\mathrm{MeO}^{-}\right] / \mathrm{M}$ & $\begin{array}{l}10^{4} \mathrm{k}_{\mathrm{obs}} \mathrm{m}^{-1} \\
\text { extrapolated }\end{array}$ \\
\hline 30 & 1.0 & 0.0 & 9.77 \\
30 & 1.0 & 1.288 & 11.56 \\
30 & 0.948 & 2.576 & II.2 \\
30 & 1.062 & 3.864 & $\mathrm{I} 1.68$ \\
\hline
\end{tabular}

Table IIc. Derived second-order rate coefficients for $\mathrm{CN}^{-}$addition to $\mathbf{5}$ in anhydrous methanol.

\begin{tabular}{lll}
\hline $\mathrm{t}\left[{ }^{\circ} \mathrm{C}\right]$ & $10^{7} \mathrm{k}_{2} \mathrm{lmol}^{-1} \mathrm{~m}^{-1}$ & $\Delta \mathrm{H} \neq / \mathrm{kJ} \mathrm{M}^{-1}$ \\
\hline 25 & $0.9 \mathrm{I}$ & $40 \pm 4$ \\
30 & 1.24 & \\
35 & $1.4 \mathrm{I}$ & \\
40 & 1.97 & \\
\hline
\end{tabular}

Table IId. First-order rate coefficients for HCN elimination from 2 in methoxide/methanol and buffered methanol solutions at $25^{\circ} \mathrm{C}$.

\begin{tabular}{|c|c|c|c|c|c|c|c|c|}
\hline $10^{5}[\mathrm{buffer}] / \mathrm{M}$ & $10^{4}[2] / \mathrm{M}$ & $10^{5} \mathrm{k}_{1}$ & $10^{5}\left[\mathrm{NEt}_{3}\right] / \mathrm{M}^{*}$ & $\mathrm{I} 0^{4}[2] / \mathrm{M}$ & $10^{5} \mathrm{k}_{1}$ & $10^{5}\left[\mathrm{MeO}^{-}\right] / \mathrm{M}$ & $10^{4}[2] / \mathrm{M}$ & $10^{5} \mathrm{k}_{1}$ \\
\hline 100 & A & 285.8 & - & & - & - & & - \\
\hline 60 & & $286 . \mathrm{I}$ & - & & $\overline{0}$ & - & & - \\
\hline$\underline{40}$ & & 280.1 & $\begin{array}{l}40 \\
20\end{array}$ & $\hat{\imath}$ & $\begin{array}{l}292.5 \\
253.6\end{array}$ & $\overline{20}$ & $\boldsymbol{A}$ & $\overline{320.3}$ \\
\hline 10 & I. 02 & 223.7 & I0 & 1.014 & 192.1 & 10 & I.095 & 277.5 \\
\hline - & & - & 8 & & 166.7 & 8 & & 242.4 \\
\hline 6 & & 170.7 & 6 & & 137.7 & 6 & & 195.1 \\
\hline 4 & & 123.6 & 4 & & 103.5 & 4 & & 137.9 \\
\hline - & & & 2 & & 60.5 & 2 & & 78.4 \\
\hline I & $r$ & 43 & $\vec{l}$ & $r$ & 35.3 & 1 & $r$ & 48.3 \\
\hline
\end{tabular}

Buffer $=\mathrm{NEt}_{3}: \mathrm{NEt}_{3} \mathrm{HCl}$

* Concentration of $\mathrm{NEt}_{3} \mathrm{HCl}$ was kept constant at $4 \times 10^{-4} \mathrm{~mol} \mathrm{l}^{-1}$; $\mathrm{k}_{1}$ is first-order rate coefficients in $\mathrm{m}^{-1}$. 
Interestingly reactions, in buffered media or methanol/methoxide ions followed first-order kinetics, irrespective of the concentration of the added reagent, up to $70 \%$ reaction followed by an upward deviation. This deviation can be attributed to a cooperative catalysis by the formed cyanide salt during the course of elimination.

$$
\begin{aligned}
& \mathrm{NaCn}\left(\text { or } \mathrm{Et}_{3} \mathrm{NNCN}^{-}\right)+\mathrm{MeOH} \rightleftharpoons \\
& \mathrm{MeONa}\left(\text { or } \mathrm{Et}_{3} \stackrel{+}{\mathrm{N}} \mathrm{H}^{-} \mathrm{OMe}\right)+\mathrm{HCN} . . .
\end{aligned}
$$

In a separate set of experiments potassium cyanide was found to increase rates of elimination from this compound. Reactions of $\mathbf{2}$ in methanol with buffer concentrations higher than $2 \times 10^{-4} \mathrm{~mol}$ $\mathrm{l}^{-1}$, i.e., in the range $4 \times 10^{-4}-10^{-3} \mathrm{~mol} \mathrm{l}^{-1}$, showed little enhancements in rate coefficients, Table IId. On the other hand, HCN elimination from 2 in methanol/methoxide ions showed a rapid consumption of the product after $c a .60 \%$ reaction at $[\mathrm{MeONa}]=2 \times 10^{-4} \mathrm{moll}^{-1}$. This decrease in product concentration may be due to addition of liberated cyanide ions to the olefinic product or substitution of cyano groups of product with methoxide ions.

Because of these difficulties we carried out the reactions in absolute methanol for the purpose of estimating the $\alpha$-leaving group or $\beta$-H kinetic isotope effects to avoid serious complications arrising from the above mentioned side reactions.

b) In $\mathbf{2}$ there is no basic centre to act as either the base for proton extraction in the elimination or the site for protonation in the presence of acids [8]. It is thus of interest to examine the effect of acid upon the reaction rate and experiments were carried out using $70 \%$ methanol as the solvent. (In this medium the reaction follows first-order kinetics in the absence of added acid.) As the reaction still proceeds in the presence of $c a \cdot 10^{-5} \mathrm{M} \mathrm{HCl}$, the effective base in the methanol or methanol-water media cannot be methoxide or hydroxide ions as the autoprotolysis constants for these solvents are so small that this concentration of acid would have totally neutralized these anionic species.

Assuming that the added acid is completely dissociated in methanol-water then either protonation of carbanion or the solvent may occur, the latter being relatively unimportant $\left(\mathrm{pk}_{\mathrm{a}} \mathrm{Me}^{\mathrm{O}} \mathrm{H}_{2} \sim-2\right)$ [12]. The added acid is not consumed during the reaction and thus acts as a negative catalyst, the ratio of its concentration to that of the carbanion increases with time. The specific rate coefficient should thus decrease with time as the carbanion concentration is increasingly repressed, and this behaviour is experimentally observed, Fig. 2a. A direct dependence of initial rate, obtained by extrapolation to time zero, with added acid concentration is thus anticipated, as shown in Fig. 2 b. The reasonably good linear plot obtained suggests that the $\mathrm{E} 1 \mathrm{cB}$ mechanism persists in the presence of these concentrations of acid. The negative slope, being fractionally less than unity $\sim 0.94$, indicates the participation of one (solvated) proton in the transition state. The participation of one solvated proton in the cyanide-loss step of the reaction provides a lower energy pathway for the elimination reaction. This acid catalyzed elimination of hydrogen cyanide bears a similarity to that of decomposition of 1,1,1,3-tetranitro-2-phenylpropane in methanolic hydrogen chloride to give $\beta$-nitrostyrene and nitroform via the slow decomposition of the rapidly formed conjugate base [13].
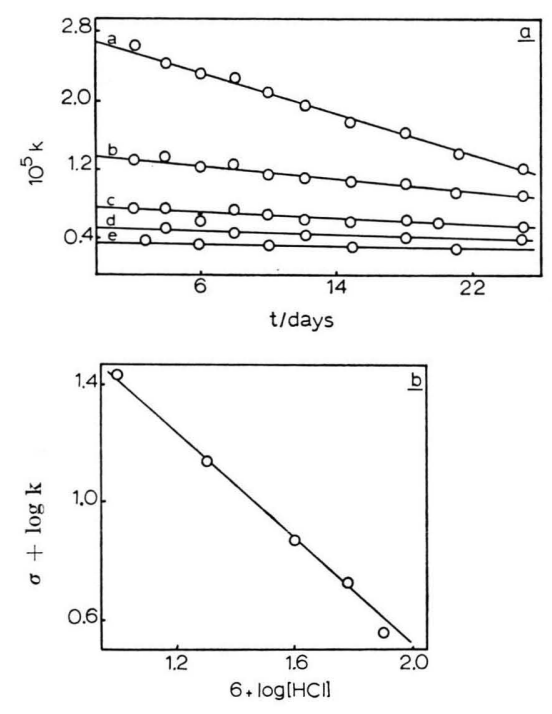

Fig. 2. a) The variation of first-order rate constants for HCN elimination from 2 in methanol/water $(7: 3)$ containing $\mathrm{HCl}$. The concentrations of $\mathrm{HCl}$ were: (a) $10^{-5}$, (b) $2 \times 10^{-5}$, (c) $4 \times 10^{-5}$, (d) $6 \times 10^{-5}$ and (e) $8 \times 10^{-5} \mathrm{ml}^{-1}$.

b) The variation of extrapolated first-order rate constants for elimination of HCN from 2 in methanol/ water $(7: 3)$ with concentration of added $\mathrm{HCl}$.

c) Increasing the polarity of the medium by the addition of water to the solvent enhances the reaction rate, with distinct change of kinetic order, Table Ia. Thus zero-order kinetics were obyed until 

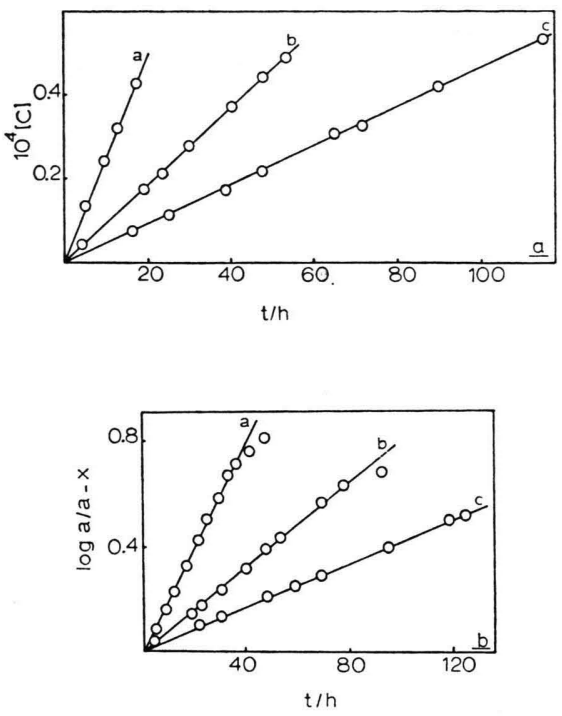

Fig. 3. a) Typical zero-order plots for $\mathrm{HCN}$ elimination from 2 in methanol/water $(9: 1)$ at (a) $35^{\circ}$, (b) $30^{\circ}$ and (c) $25^{\circ} \mathrm{C}$.

b) Typical first-order plots for HCN elimination from 2 in methanol/water $(7: 3)$ at (a) $35^{\circ}$, (b) $30^{\circ}$ and (c) $25^{\circ} \mathrm{C}$.

the water-methanol ratio was $7: 3$ whereupon firstorder kinetics were observed, Fig. 3a-3 b. Although the charged intermediate and eliminated cyanide ion will both be stabilized by increasing solvent polarity, the greater acidity of water, as compared with methanol, will also favour reprotonation of the carbanion, thus shifting the kinetics toward firstorder. The mechanism should therefore change from $(\mathrm{E} 1)_{\text {anion }}$ towards $(\mathrm{E} 1 \mathrm{cB})_{\mathrm{R}}$. The energy of activation decreases slightly with increasing water content of the medium suggesting that the transition state becomes more reactant (i.e., carbanion-like [14]), but non-linear plots for log $\mathrm{k}$ versus $\log \left[\mathrm{H}_{2} \mathrm{O}\right]$ were obtained. Increasing the basicity of the medium was found to similarly decrease the activation energy for elimination from dimethyl-2-arylethylsulphonium ions [15].

The facile $\beta$-hydrogen exchange observed to date for all polycyanoethane derivatives precludes the observation of primary kinetic hydrogen isotope effects for elimination from these systems. Equilibrium and solvent isotope effects are to be expected, however, and the data for compound 2 have been reported [1]. Primary leaving group isotope effects are expected for an ElcB mechanism and have indeed been observed [1]. Hydrogen isotope effects $\leqslant 1.0$ have been reported [16], so our value of
$\mathrm{k}_{\mathrm{H}} / \mathrm{k}_{\mathrm{D}}=1.2$ is not unreasonable. An approximately equal effect upon the equilibrium steps (forward and reverse) is normally assumed [17], although it is probable that the carbanion will be better solvated by the protic medium. However, the lower basicity of methanol implies a carbanion concentration in the protic solvent and thus any effect in favour of either medium will be slight, as will effect upon the second step of the reaction. A further confirmation to the previous argument is that HCN elimination from 2 in methan- $\left[{ }^{2} \mathrm{H}_{1}\right]$-ol, which is regarded as a stronger base than methanol [18], followed zeroorder kinetics up to $85 \%$ reaction.

Closely related results were obtained for water elimination from 9-fluorenylmethanol [19]. The solvent isotope effect in methanol for water elimination from 9-fluorenylmethanol is 0.36 indicative of $\mathrm{E} 1 \mathrm{cB}$ elimination. Thus the value obtained for hydrogen cyanide elimination from $\mathbf{2}$ has the same range, i.e., $\leqslant 1$, thus supporting reaction via an analogous mechanism.

Elimination from 3: This polycyanide also undergoes zero-order elimination of hydrogen cyanide in anhydrous methanol to give $>95 \%$ yield of the corresponding olefin, similar to the reaction of $\mathbf{2}$ and other polycyanides studied previously [8] under identical conditions. The $\beta$-hydrogen of 3 was exchanged instantaneously when a drop of $\left[{ }^{2} \mathrm{H}_{4}\right]$ methanol was added to the solution of this compound in $\mathrm{CDCl}_{3}$, as detected by NMR. The spontaneous exchange of $\beta$-hydrogen in compounds 2-5 suggests comparable acidities, hence differences in reaction rates could be attributed to different substitution on $\mathrm{C}_{\alpha}$. In this case, one also may assume substantial formation of the carbanion followed by a very slow ejection of the cyanide ion to give the olefin i.e., the reaction rate is independent on 3 and this is compatible with $\left(\mathrm{E}_{1}\right)_{\text {anion }}$ varient [6].

Surprisingly, HCN eliminates from $3 \sim 1.4$ times faster than $\mathbf{2}$ and with lower energy of activation, Table 1 c. This can be explained on the basis of structural differences which would allow rotation of the two phenyl groups about their bonds to the aliphatic $\mathrm{C}_{\alpha}$ in the former. However, the two phenyl groups may occupy two different planes due to steric interactions between them. Obviously, a similar rotation is impossible in 2 because of the rigid fluorenyl system. The non-planarity of the phenyl groups of 3 resulted in a decreased resonance energy of its olefinic product compared with that 
of 2 as shown the UV spectra. Compound 3 has $\lambda_{\max }=318 \mathrm{~nm}$ with $\varepsilon_{\max }=14,510$ while 2 has $\lambda_{\max }=346$ and $\varepsilon_{\max }=18,900$ in absolute methanol.

It is likely that the release of the strain, leading to a more loose transition state, in going from 2 to 3 results in a faster rate of elimination from the latter. It is also expected that changing the steric requirements of $\mathrm{C}_{a}$ may bring about a change in its rehybridization, and this is reflected on the ratedetermining step, $k_{2}$, which is the ejection of cyanide ion from $\mathrm{C}_{\alpha}$ of the corresponding conjugate base. This may render the transition state of 3 more carbanion-like than of $\mathbf{2}$ and more product-like than of 5 . This may lead to the conclusion that the product stability is not the sole factor dominating the $\mathrm{E} 1 \mathrm{cB}$ reaction pathway.

Addition of an aprotic solvent such as benzene up to $20 \%$ by volume to the reaction medium led to a relatively small decrease in the specific rate coefficients associated with an earlier deviation from zero-order linearity. Increase of benzene proportions to $30 \%$ shifted the reaction to half-order kinetics. Increase of concentration of benzene to $50 \%$ gave a reasonable first-order plot, Table Ic. In general, successive additions of benzene will decrease the dielectric constant of the medium and most probably would suppress the ionization of the tricyanide, $\mathrm{k}_{1}$. Consequently, the concentration of the conjugate base decreases. This decrease in conjugate base concentration may be responsible for the earlier deviation from zero-order kinetics observed in methanol-benzene solvents. Moreover, benzene is not as good as methanol in solvating the leaving group, $\mathrm{CN}^{-}$, when it departs from the conjugate base. This also leads to retardation in $\mathrm{k}_{2}$ and a decrease in the overall reaction rate, $k_{1} k_{2} / k_{-1}$. For solvents richer in benzene i.e., $40 \%$ and $50 \%$, retardation of $k_{1}$ and $k_{2}$ may result in a steady concentration of the carbanion i.e., first-order rate dependence on polycyanide concentration with a decrease in overall reaction rate constant. Thus addition of an aprotic solvent resulted in a change in the reaction mechanism from $\left(\mathrm{E}_{1}\right)_{\text {anion }}$ to $(\mathrm{E} 1 \mathrm{cB})_{\mathrm{R}}$, a phenomenon observed when a protic solvent such as water is added to the reaction media of $\mathbf{2}$.

Thus it seems likely that in this case $\left(\mathrm{E}_{1}\right)_{\text {anion }}$ mechanism could be changed to $(\mathrm{E} 1 \mathrm{cB})_{\mathrm{R}}$ on addition of either a polar solvent such as water or an aprotic solvent such as benzene. The latter situation is similar to that observed by Rappoport et al. $[3,7]$ in hydrogen cyanide elimination from 2,6-dimethyl4-(1,1,2,2-tetracyanoethyl)aniline in chloroform catalyzed by amines of different basicities. A highly basic amine such as triethylamine or $n$-butylamine reacted with the former tetracyanide to give substantial concentrations of the corresponding carbanion in chloroform i.e., $\left(\mathrm{E}_{1}\right)_{\text {anion }}$ mechanism. On the other hand, catalysis by weaker amines such as pyridine, aniline or $\mathrm{N}, \mathrm{N}$-dimethyl-aniline resulted in a lower ionization of the cyano compound, thus shifting the mechanism to $(\mathrm{E} 1 \mathrm{cB})_{\text {ip }}$ with overall second-order kinetics and zero-order in the amine within the run $[3,7]$.

Hydrogen cyanide elimination from 4: It was the pious hope to study HCN elimination from compounds 6-8 with $\mathrm{C}_{\alpha}-\mathrm{H}$ and different substituents on the 4-position on the aromatic ring. This was planed to relate rate constants and enthalpies of activation to the transition state geometries, if possible. However, this was not possible because elimination from 6-8 proceeds up to $20-30 \%$ with irregular kinetic behaviour followed by a build-up of other compounds which were difficult to identify and these were not investigated further. Thus results for comparison were not at hand.

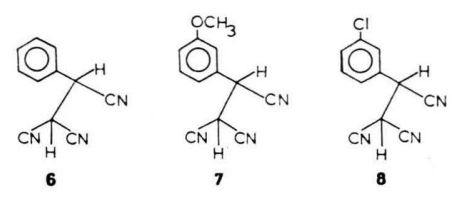

However, $\alpha$-C- $-\mathrm{CH}_{3}$ substituent i.e., tricyanide (4), underwent $>96 \%$ elimination in anhydrous methanol. The almost quantitative olefin formation form 2-4 but not from 5-8 confirms the observation that the stability of the olefinic product (the most substituted) is a driving force in elimination, but not necessarily the sole factor controling the reaction pathway. Similar to 2 and 3 , the $\beta$-hydrogen of 4 exchanges spontaneously when allowed to react with deuterated solvents such as methan- $\left[{ }^{2} \mathrm{H}_{1}\right]$-ol. This may also suggest a non-steady state concentration of carbanion for solutions of $\mathbf{4}$ in anhydrous methanol leading to zero-order kinetics i.e., elimination via $\left(\mathrm{E}_{1}\right)_{\text {anion }}$ route. After $c a .60-70 \%$ reaction appreciable concentration of hydrogen cyanide is accumulated and thus could possibly enhance both $\mathrm{k}_{-1}$ and $\mathrm{k}_{-2}$, and this results in deviation from zeroorder kinetics. 
Replacing the $a$-phenyl group with a methyl group, indeed decreases the resonance energy of the olefinic product in the same direction. Polycyanide (4) has $\lambda_{\max }=286 \mathrm{~nm}$ and $\varepsilon_{\max }=12,475$ in methanol. Nevertheless, hydrogen cyanide elimination from 4 is $\mathbf{1 . 1}$ faster than that from $\mathbf{2}$ under similar conditions, Table Ic. This may support the suggestion that the release of strain and decrease in steric requirements about $\mathrm{C}_{\boldsymbol{\alpha}}$ would lead to a looser transition state, thus a faster reaction rate. Similar to the reactions of 3 , added benzene to the reaction medium resulted in decreasing the reaction rate with continuous drift in the reaction order to unity (Fig. 4a). In $70 \%$ methanol, the reaction is halforder, whereas in $60-40 \%$ methanol, the reaction became first-order in 4 .

Surprinsingly, in $30 \%$ methanol a continuous decrease in the specific rate coefficients is observed with the increase in the reaction percentage. An initial rate coefficient was determined via extrapolation from a plot of specific rate constants against time, Table Ic. The data suggest that in solvents richer in benzene, the reaction has shifted further to $(\mathrm{E} 1 \mathrm{cB})_{\text {ip }}$ from $(\mathrm{E} 1 \mathrm{cB})_{\mathrm{R}}$ variant, viz.

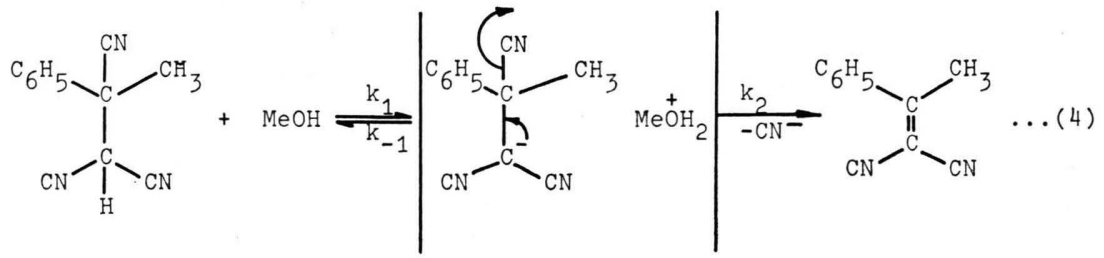

A further decrease in methanol to 20 and $10 \%$ by volume has resulted in only $5-10 \%$ elimination over a period of three months. Brønsted plots of $\log \mathrm{k}_{1}$ against $\log [\mathrm{MeOH}]$ gave a smooth curve rather
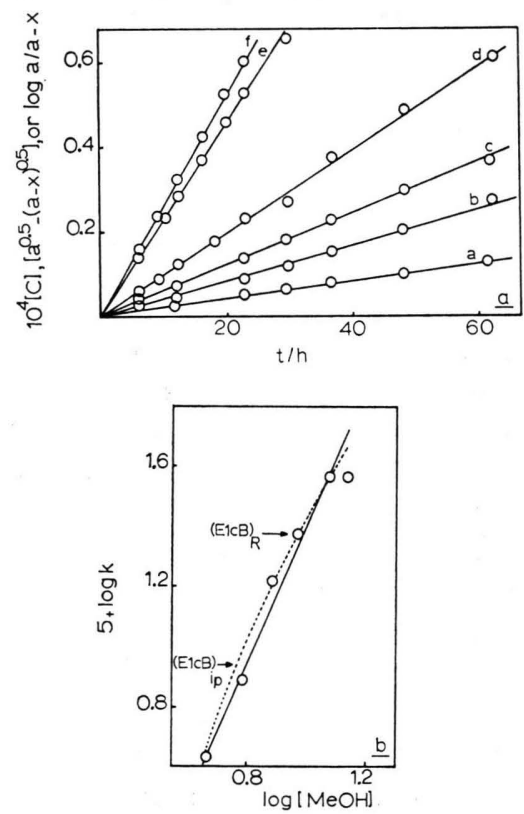

Fig. 4. a) Typical plots for $\mathrm{HCN}$ elimination from 4 in methanol/benzene at $40{ }^{\circ} \mathrm{C}$, where: (f) zero-order plot in $(9: 1),(e)$ zero-order plot in $(4: 1)$, (d) half-order plot in (7:3) methanol/benzene mixtures. (c), (b) and (a) are first-order plots in $(3: 2),(1: 1)$ and $(2: 3)$ methanol/ benzene solutions respectively.

b) Bronsted plot of $\mathrm{HCN}$ elimination from 4 in methanol/benzene solvents. than a linear relationship, Fig. 4 b. At moderate concentrations of methanol $90-50 \%$ there is a tangential slope of 1.7 representing the number of methanol molecules solvating the $(\mathrm{E} 1 \mathrm{cB})_{\mathrm{R}}$ transition state. At higher proportions of benzene $50-70 \%$, the $(\mathrm{E} 1 \mathrm{cB})_{\text {ip }}$ transition state becomes more selectively solvated and the ease of exchange of methanol molecules in the solvation seeth with those in the bulk solvent are restricted relative to solvents higher in methanol. This results in a higher number of methanol molecules solvating the $(\mathrm{E} 1 \mathrm{cB})_{\text {ip }}$ transition state i.e., 2.7, Fig. 4 b.

Elimination from 5: In the absence or presence of added base, first-order kinetics was obyed for the first $40 \%$ of the reaction, but after this the rates decrease and eventually equilibria are attained [1]. The position of equilibrium in a given reaction is both base and temperature dependent and a typical first-order plot is shown in Fig. 5a. First-order rate coefficients were determined from the initial rate data and the values obtained in methanol solution are shown in Table II c. Analysis of the kinetic data, Fig. 5a-c, Table IIa, implies rapid proton extraction relative to ejection of cyanide ions. In the presence of added sodium methoxide at $30{ }^{\circ} \mathrm{C}$ the reaction rate increases, Table II b, although the rate enhancement is small. The addition of weaker bases to the reaction medium, e.g., triethylamine, piperidine or morpholine, resulted in rate changes within the experimental error. These results could be 


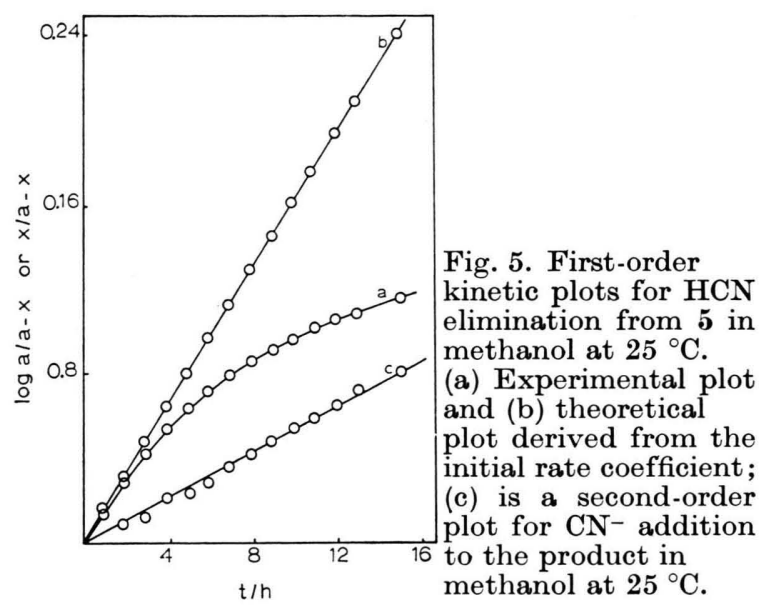

compared with Rappoport's earlier studies of 2-aryl-1,1,2-tricyanoethanes [20].

Studies of the reaction of 5 in methanol and of (5-D) in methan- $\left[{ }^{2} \mathrm{H}_{1}\right]$-ol gave a value of 2.8 for the observed isotope effect, $\mathrm{k}_{\mathrm{H}} / \mathrm{k}_{\mathrm{D}}$. This is an unexpectedly high value for an equilibrium plus solvent isotope effect. Such values are usually close to, or less than, unity, and a primary effect is precluded by the rapid exchange of the $\beta$-hydrogen atom. As the equilibrium isotope effect of the initial proton extraction should be unity, then the major contribution to the observed value arises from a solvent effect upon the cyanide ion loss [1].
Several authors have recently pointed out that the relationship of isotope effects to transition state geometries should be treated with circumspection, as well as the similar use of $\operatorname{Br} \varnothing n s t e d ~ \beta$-values [21,22]. Although numerous examples are known in which the use of such relationships has given results which are both reasonable and in accord with expectations $[14,15]$, there are also examples of the failure of such correlations [23, 24].

Certain qualitative conclusions may however be drawn from the data presented here. Thus the influence of electron withdrawing groups at the $\alpha$-carbon atom is predicted to make the transition state more product-like $[14,25]$. Indeed, energies of activation of $\mathbf{2}$ and $\mathbf{5}$ in anhydrous methanol accord with a more product like transition state for $\mathbf{2}$. Leaving group isotope effects are also in accordance with this [1]. (If the phenyl ring is considered to be an electron withdrawing substituent then the results are as would be predicted, ignoring the added geometrical constraint upon the 'phenyl' substituent in 2 and any effects of the dimethylamino group in 5.) The kinetic data presented here thus support the conclusions of the isotope effect studies reported previously [1], and suggest that product stability is not the sole factor determining the transition state geometry.

We are grateful to the National Research Council of Canada for financial support.
[I] Preceding paper, F. M. Fouad and P. G. Farrell, Z. Naturforsch. 33 b, 1496 (I978)

[2] P. G. Farrell and J. Newton, J. Chem. Soc. B 1970 , 1630; F. M. Fouad, P. G. Farrell, and A. G. Abdel-Rehiem, Tetrahedron Lett. 1974, 3355.

[3] Z. Rappoport and E. Shohamy, J. Chem. Soc. B 1971, 2060.

[4] A. Fry, Chem. Soc. Rev. 1, I63 (1972).

[5] W. T. Ford, Acc. Chem. Res. 6, 410 (I973).

[6] F. G. Bordwell, Acc. Chem. Res. 5, 374 (1972)

[7] Z. Rappoport and R. Ta-Shma, J. Chem. Soc. B 1971, 871, I46I ; Z. Rappoport and P. Peled, J. Chem. Soc. Perkin II 1973, 616; Z. Rappoport and A. Topol, ibid. 1972, I823.

[8] P. G. Farrell and A. G. Abdel-Rehiem, unpublished data.

[9] B. C. McKusick, R. E. Heckert, T. L. Cairus, D. D. Coffman, and H. F. Mower, J. Am. Chem. Soc. 80, 2806 (1958); H. D. Hartzler, J. Org. Chem. 31, $2654(1966)$; B. B. Corson and R. W. Stoughton, J. Am. Chem. Soc. 50, 2825 (1928).

[10] A. I. Vogel, Practical Organic Chemistry, p. 169, Longmans, London 1966.
[11] C. D. Ritchie and P. D. Heffley, J. Am. Chem. Soc. 87, 5402 (1965).

[12] J. B. Hendrickson, D. J. Cram, and G. S. Hammond, Organic Chemistry, p. 306, McGraw-Hill Book Co., London 1970.

[13] J. Hine and L. A. Kaplan, J. Am. Chem. Soc. 82, 2915 (1960).

[14] E. R. Thornton, J. Am. Chem. Soc. 89, 2915 (1967); L. J. Steffa and E. R. Thornton, ibid. 89, 6149 (1967); D. A. Winey and E. R. Thornton, ibid. 97, 3102 (1975).

[15] A. F. Cockerill, J. Chem. Soc. B 1967, 964.

[I6] L. R. Fedor, J. Am. Chem. Soc. 91, 913 (1969).

[17] R. A. More O'Ferrall, J. Chem. Soc. B 1970, 260.

[18] R. L. Showen, Prog. Phys. Org. Chem. 9, 275 (1972).

[19] R. A. More O'Ferrall, J. Chem. Soc. B 1970, 274, 268.

[20] M. Albeck, S. Hoz, and Z. Rappoport, J. Chem. Soc. Perkin II 1972, 1248.

[2I] R. P. Bell, Chem. Soc. Rev. 3, 513 (I974).

[22] F. G. Bordwell and W. J. Boyle, J. Am. Chem. Soc. 93, 5II (I97I). 
[23] c.f. No maximum primary kinetic isotope effect has been observed in E I cB dehydrobromination from phenethyl systems catalysed by potassium $t$-butoyide in $t$-butanol with the increase in the electron withdrawal nature of the para-substituent i.e., from 4- $\mathrm{H}_{3} \mathrm{C}-\mathrm{O}$ - to $4-\mathrm{O}_{2} \mathrm{~N}$-, L. F. Blackwell, P. D. Buckley, K. W. Talley, and A. K. H. MacGibbon, J. Chem. Soc. Perkin II 1973, I69.
[24] L. F. Blackwell and J. L. Woodhead, J. Chem. Soc. Perkin II 1975, 234.

[25] P. G. Smith and A. N. Bourns, Can. J. Chem. 52, 749 (1974); A. M. Katz and W. H. Saunders, J. Am. Chem. Soc. 91, 4469 (1969). 